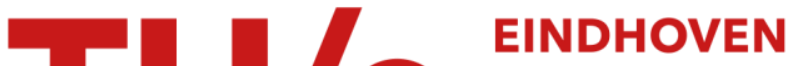 UNIVERSITY OF TECHNOLOGY
}

\section{Opportunities for providing sustainability and care in existing homes through smart solution}

\section{Citation for published version (APA):}

Dominicus, M. M. T., \& Mohammadi, M. (2012). Opportunities for providing sustainability and care in existing homes through smart solution. Gerontechnology, 11(2), 224-225. https://doi.org/10.4017/gt.2012.11.02.516.00

DOI:

10.4017/gt.2012.11.02.516.00

Document status and date:

Published: 01/01/2012

\section{Document Version:}

Publisher's PDF, also known as Version of Record (includes final page, issue and volume numbers)

\section{Please check the document version of this publication:}

- A submitted manuscript is the version of the article upon submission and before peer-review. There can be important differences between the submitted version and the official published version of record. People interested in the research are advised to contact the author for the final version of the publication, or visit the $\mathrm{DOI}$ to the publisher's website.

- The final author version and the galley proof are versions of the publication after peer review.

- The final published version features the final layout of the paper including the volume, issue and page numbers.

Link to publication

\section{General rights}

Copyright and moral rights for the publications made accessible in the public portal are retained by the authors and/or other copyright owners and it is a condition of accessing publications that users recognise and abide by the legal requirements associated with these rights.

- Users may download and print one copy of any publication from the public portal for the purpose of private study or research.

- You may not further distribute the material or use it for any profit-making activity or commercial gain

- You may freely distribute the URL identifying the publication in the public portal.

If the publication is distributed under the terms of Article 25fa of the Dutch Copyright Act, indicated by the "Taverne" license above, please follow below link for the End User Agreement:

www.tue.nl/taverne

Take down policy

If you believe that this document breaches copyright please contact us at:

openaccess@tue.nl

providing details and we will investigate your claim. 


\section{Track: Health - Comfort - Self-esteem Symposium: Research and education at TU/e}

R.M.M. FONVILLE (Convener). The ageing society: Health related research \& education at Eindhoven University of Technology. Gerontechnology 2012;11(2):223; doi:10.4017/gt.2012.11.02.640.00 Participants: M.T.T. DOMINICUS, M. MOHAMmadI, M. SINOO, J. VAN HOOF, H.S.M. KORT, D. BERA, K.M. VAN HEE, Y. KOKS, M.P.W.J. VAN OSCH, B. VAN NINHUIIS, T. MOTOASCA, D.J. VAN DER PIJL, P. VERSTEGEN, E.A. LOMONOVA (all from The Netherlands). ISSUE Health-related research and education at Eindhoven University of Technology. CONTENT In the field of healthcare, our society faces numerous challenges. These include an ageing population, a growing number of people with lifestyle-related diseases like obesity and diabetes, and other chronic diseases, as well as rapidly rising staff shortages. These challenges require new products and services in the healthcare system, and technology plays a crucial role in addressing those challenges. In the Strategic Area Health@TU/e (Eindhoven University of Technology), we aim to develop people-centric technology that is self-explanatory and user-friendly. Two things are pivotal: (i) We use our highend technical knowledge as the basis for developing suitable technological solutions for people. Often new innovations start in the complex and expensive hospital environment, but it is our strategic intent to ensure that these solutions are engineered in such a way that they can be introduced into first-line care and even self-care environments. The ultimate goal is to lower costs of the healthcare system and increase quality of life in our ageing society. (ii) The organization of care and the associated IT-systems focus on increasing patient independence. We want to make technology more accessible, also for elderly people, which in turn will make self-care easier. This goal is achieved, in part, through open innovation and sharing knowledge. We take an integrated approach to research, working together with other universities, medical centers, hospitals, care facilities, healthcare insurers, companies, and governments - both nationally and internationally. The approach to identify the Health@TU/e themes and programs can best be described as "societal driven". The societal needs in the health domain were defined by means of a stakeholder analysis. The resulting vision has been linked with bottom-up defined research competences. Over 300 researchers from nine different departments participate in Health@TU/e and are committed to the prevention, early diagnosis, and more effective treatment of diseases, as well as to promoting healthy lifestyles and living environments. Apart from research and valorization, the TU/e focusses on healthcare-related themes in the curriculum of undergraduate and graduate students. STRUCTURE Roel Fonville will describe the diversity of health related research at TU/e and will motivate the chosen structure and organization of Health@TU/e. Next, four TU/e researchers will present their research projects. CONCLUSION With the contributions in this session we will show the great opportunities of technology for sustainable healthcare solutions in an ageing society.

Keywords: health, smart intervention, smart environment, smart diagnosis

Affiliation: Eindhoven University of Technology, Eindhoven, Netherlands; E: r.fonville@tue.nl

\section{M.M. SINOO, J. VAN HOOF, H.S.M. KORT. Light conditions in the nursing home. Gerontechnology} 2012;11(2):223-224; doi:10.4017/gt.2012.11.02.132.00 Purpose In the Netherlands, the prevalence of visual impairments is the highest among the subgroup of nursing home residents. Over 40 percent are estimated to have visual impairments ${ }^{1}$. Older adults experience visual problems due to biological aging or eye disease ${ }^{2}$. These problems can affect several visual functions as well as daily functions in general ${ }^{3,4}$. Providing appropriate lighting of sufficient intensity and color temperature $(\mathrm{CT})$, and making use of capabilities of the visual environment in the nursing home ${ }^{4}$ is one of the tasks for professional carers.Light conditions were measured in order to find out to what extent older adults live with the proper lighting conditions. With these data, we wanted to enhance the awareness among care professionals of how light conditions affect the daily lives of the nursing home residents. Moreover, care professionals and technical staff could make the right improvements to the nursing home environment based on the outcomes. Method We assessed light conditions (Konica Minolta chromameter CL-200) in seven nursing homes in the Netherlands. Light conditions were measured in places where residents spend most of their time during the day. In total, 59 living rooms and corridors were assessed in this study. Horizontal and vertical illuminances as well as CT were measured and compared to the values given in a 
guideline by the Dutch Society for Illumination ${ }^{5}$. The study was performed between October 2009 and the end of March 2010 at daytime between 10:00 and 15:00 hours. By measuring in autumn, winter and early spring, the contribution of daylight to the indoor illuminance levels was kept at a minimum. Results \& Discussion In general lighting conditions encountered in the nursing homes were poor. Four-fifths of the measured illuminances in the common rooms were below the 1,000 Ix threshold. Illuminances in the corridors fell below the $200 \mathrm{Ix}$ threshold in at least three quarters of the measurements. This means that nursing home residents may have difficulty carrying out tasks and could fall during transfers. The CT of light to which nursing home residents were exposed, fell below the reference value for daylight of 5,000 K with median scores of 3,400 to 4,500 K. High CT of light, in combination with higher illuminances, may positively affect the biological clock, resulting in better sleep quantity and quality. Nursing home staff should be aware of these data in order to arrange better light conditions. Technical staff should be aware that lighting guidelines are not specifically developed for older adults. Special attention should be paid to the fact that older adults need more light than younger persons to perform Activities of Daily Living (ADL).

\section{References}

1. Limburg H, Keunen JEE. Blindness and low vision in The Netherlands from 2000 to 2020 - modeling as a tool for focused intervention. Ophthalmic Epidemiology 2009;16(6):362-369; doi:10.3109/09286580903312251

2. Bouma $\mathrm{H}$, Weale RA, McCreadle $\mathrm{C}$. Technological environments for visual independence in later years. Gerontechnology 2006;5(4):187-195; doi:10.4017/gt.2006.05.04.001.00

3. Hoof J van, Kort HSM, Duijnstee MSH, Rutten PGS, Hensen JLM. The indoor environment and the integrated building design for older people with dementia. Building and Environment 2010;45(5):1244-1261; doi:10.1016/j.buildenv.2009.11.008

4. Boyce PR. Lighting for the elderly. Technology and Disability 2003;15(3):165-180

5. Stoer GW. Licht, welzijn en de ouder wordende mens. First edition. Ede, Netherlands: Nederlandse Stichting Voor Verlichtingskunde; 2006

6. Sinoo MM, Hoof J van, Kort HSM. Lighting conditions for older adults in the nursing home. Building \& Environment 2011;46(10):1917-1927;

doi:10.1016/j.buildenv.2011.03.013

Keywords: illuminance, nursing home, light, lighting, colour temperature, older adults

Affiliation: University of Applied Sciences, Utrecht,

Netherlands; E: marianne.sinoo@hu.nl

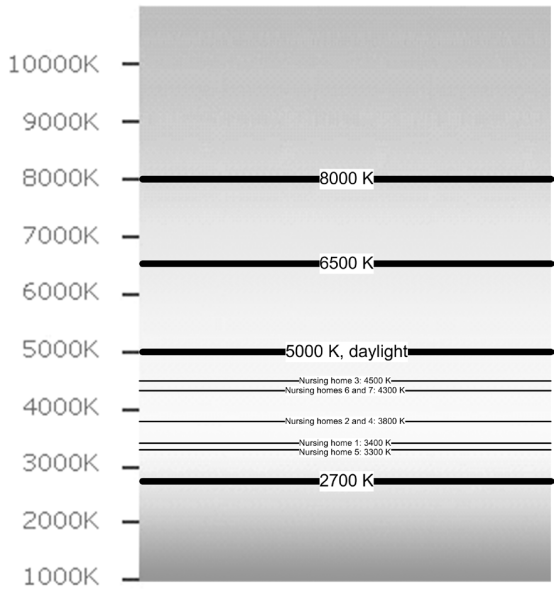

Figure 1. Medians of measured colour temperature in seven nursing homes ${ }^{6}$ Full paper: No

\section{M.M.T. DOMINICUS, M. MOHAMMADI. Opportunities for providing sustainability and care in ex-}

isting homes through smart solutions. Gerontechnology 2012;11(2):224-225; doi:10.4017/gt.2012.11.02.516.00 Purpose In the coming decade, a huge increase in demand is expected for public housings for older adults in the Netherlands. However, public housing corporations are not planning to build new homes in the near future. Current housing stocks do not fulfill to the requirements for care ${ }^{1}$ and energy saving ${ }^{2}$. One solution to this problem is to transform existing homes into integrated and smart environments that corresponds to requirements and leads to healthier and independent living in combination with sustainable goals. At the moment, some housing corporations have pilots ${ }^{4}$ ongoing on smart and sustainable homes that are also suitable for providing care and supporting aging-in-place ${ }^{3}$. The purpose of this study is therefore to define the opportunities, challenges and criteria for developing sustainable care home concepts and solutions in the existing housing stocks in the light of these pilots. Method Relevant information will be gathered by performing interviews and visiting sites on (i) the per- 
spective of the housing corporation, (ii) the specific approach of the project and underlying principles, (iii) the level of integration of the technology, (iv) financial aspects and exploitation possibilities, (v) long-term maintenance, (vi) processes, and (vii) the satisfaction level of the residents. Results \& Discussion Application of these smart solutions in existing homes calls for an approach which integrates sustainability and care at home. This study aids the housing corporation in creating an inclusive renovation plan for care homes and forms a recommendation for the development of a policy scheme for upgrading existing homes.

\section{References}

1. Regionale Commissie Gezondheidszorg Zuid-Holland Noord. Woonzorgmonitor 2010. Huidige en toekomstige vraag naar en aanbod van woonzorgvoorzieningen in beeld. Leiden: Regionale Commissie Gezondheidszorg Zuid-Holland Noord; 2010

2. Taskforce $\mathrm{CO}_{2}$. Projectplan Taskforce $\mathrm{CO}_{2}$. Onderzoek bestaande voorraad, Lisserbroek: Tasforce $\mathrm{CO}_{2}$; 2011

3. Henkemans B, Olivier A, Alpay L, Dumay CM. Aging in place: self-care in smart home environments. In: Al-Qutayri MA, editor. Smart Home Systems. Rijeka: In-Tech; 2010

4. Vestia Noord Nederland. IJsselhave in Doesburg; 2009; www.vestia.nl/NoordNederland/OverVestia/

ActiviteitenEnProjecten/Pages/IJsselhavenDoesburg.aspx; retrieved January 2, 2012

Keywords: housing, sustainability, renovation, existing homes, public housing, care

Affiliation: Eindhoven University of Technology, Eindhoven, Netherlands;

E:m.m.t.dominicus@tue.nl

Full paper: No

M.P.W.J. VAN OSCH, D. BERA, Y. KOKS, K.M. VAN HEE. Tele-operated service robots for household and care. Gerontechnology 2012;11(2):225-226; doi:10.4017/gt.2012.11.02.194.00 Purpose Service robots are a relatively new branch of robotics after the successful industry robots and the experimental humanoids. Service robots are supposed to perform tasks that normally are done by humans in particular daily life activities. However they do not have to do it in the same way as humans and neither do they not have to look like a human. Service robots have to operate in environments meant for humans so they have to navigate in environments with unforeseen moving objects and subjects, to mention only one of the challenges. This paper is based on our experience with a tele-operated service robot, named Rose. Tele-operated means that Rose is not completely autonomous but that it is remotely controlled by a human operator. The human operator has the option to control the robot manually or provide indications to carry out complex coordinated procedures (eg. move and grab object). Tele-operated service robots have a wide range of applications, such as in the building industry to carry and place heavy objects, or in the security business. We focused on daily life household tasks. Experiments with Rose were performed in a field lab setting, for the care of elderly people. They need attention several times a day, but in total not more than two hours. This means that one operator can service several homes. This results in a five-fold productivity improvement of care takers. After an introduction on tele-operated service robots, we concisely present the system design of Rose. Then we sketch the field lab experiments and we consider the lessons learned. Based on this information we present some scenarios for the future of tele-operated service robots for caretaking and household tasks. Both the technical and the application aspects will be covered. Method First, a number of general purpose use cases ${ }^{1}$ covering daily household activities such as warming a meal, picking and placing objects, turning on the light etc. were defined. From these use cases, the system architecture of Rose was derived using a construction technique called correctness by construction $^{2}$. This construction technique guarantees deadlock freedom and livelock freedom. The software development was carried out using the popular Robot Operating System (ROS) framework ${ }^{3}$. Four rounds of tests covering all use cases were carried out by nurses from a care organization called Zuid Zorg in Waalre, the Netherlands. In the first three sessions the cockpit was located in a room next to the robot. In the fourth session, the cockpit was located in Veldhoven, another nearby town, while the robot remained in Waalre. Results from each test round were used to improve the software of Rose. Results \& Discussion From the results of all test sessions we were 
servicing multiple Table 1. Time trials (in Minutes)

homes (Table 1).

Furthermore, con-

sistency in per-

formance can be

achieved by ex-

ploiting the robot's autonomy.

\begin{tabular}{|c|c|c|c|}
\hline Activity & $\begin{array}{r}\text { Operator: } \\
\text { Manual }\end{array}$ & $\begin{array}{l}\text { Ceclile } \\
\text { Shared Autonomy }\end{array}$ & Shared Autonomy \\
\hline Driving to the Fridge & 2.25 & 2.18 & 2.28 \\
\hline Picking up Object & 5.15 & 0.57 & 0.26 \\
\hline Driving to the Table & 2.40 & 2.15 & 2.16 \\
\hline Putting down object & 2.47 & 0.58 & 0.57 \\
\hline End Time & 12.27 & 5.48 & 5.27 \\
\hline
\end{tabular}

\section{References}

1. Osch M. Teleoperated Service Robot ROSE, TU/e - ROSE 2010. Proceedings of Symosium: Zorg op Afstand met Robots, Eindhoven; 2010

2. Bera D, Hee KM van, Werf JMEM van der. Designing Weakly Terminating ROS Systems. Applications and Theory of Petri Nets (33th International Conference, Petri Nets 2012). Lecture Notes in Computer Science; 2012

3. Quigley M, Gerkey B, Conley K, Faust J, Foote T, Leibs J, Berger E, Wheeler R, Ng A. ROS: an open-

source Robot Operating System. Proceedings of ICRA Workshop on Open Source Software; 2009

Keywords: service robots, home-care, correctness by construction

Affiliation: Eindhoven University of Technology, The Netherlands; E: d.bera@tue.nl

Full paper: doi:10.4017/gt.2012.11.02.194.693

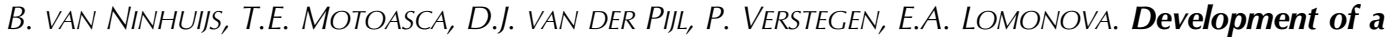
smart arm support for daily-life activities and entertainment. Gerontechnology 2012;11(2):226-227; doi:10.4017/gt.2012.11.02.255.00 Purpose Today's society is becoming aware of the long-term effects of the strong increase in ageing population while the numbers of caregivers decreases. It will become a difficult and expensive task to provide all the elderly people with the care they require. Many older adults are mentally healthy enough to take care of themselves, but their body, especially their muscle functionalities, deteriorate due to aging. This means that the more the muscles deteriorate, the more they will be dependent on caregivers. To provide some level of independence, while the impairments are not very severe, assistive devices can help with their daily activities ${ }^{1}$. For most basic daily activities, like eating, drinking, washing etc., arm functionalities are essential. To provide assistance and enhancement of these functionalities, arm support systems can be used that provide support for all user movements. These movements can also be used to trigger games if the arm support is developed as a smart system with multiple functionalities. This way not only support is offered, but it is also possible to play games where the impaired user will be entertained and, at the same time, the arm muscles will be trained to improve arm functionality. Method The already commercially available arm supports can be categorized in four groups: simple arm supports with only horizontal support ${ }^{2}$, arm supports with only gravitation compensation using mechanical springs ${ }^{3}$, arm supports where the spring tension for the gravitation compensation is adjusted using an electrical machine $\mathrm{e}^{4}$ and, arm supports that are completely electrically actuated in all directions ${ }^{5}$. However, the fully actuated arm supports are designed for rehabilitation purposes and are too big to be used at home. Therefore there is a need for an ambulatory actuated arm support which assists the elderly with their daily living activities. This arm support can have added entertainment and training value if equipped with a serious gaming functionality. To verify the entertainment value of such arm supports a prototype was developed (Figure 1). Results \& Discussion Tests on the prototype (Figure 1) have been performed with elderly people who suffer from deteriorated muscles due to ageing. Playing games using the arm support as a joystick was experienced as a fun activity; muscle training as a byproduct of gaming movements was also experienced as enjoyable. However, the tests were conducted with a mechanical arm support that only allows some arm movements. To provide the user with an optimal and interactive arm support for any motion direction, actuators need to be implemented in the arm support, resulting in a small, light-weight and flexible novel ambulatory smart arm support. This novel arm support can be used both for assisting the daily activities as 
Track: Health - Comfort - Self-esteem

Symposium: Research and education at TU/e

for rehabilitation purposes. [The research leading to these results has received funding from the Dutch "Pieken in de Delta" program, project McArm no. PID102055.]

\section{References}

1. Mann WC. Smart Technology for Aging, Disability, and Independence - The State of the Science. Hoboken: John Wiley; 2005

2. ZoncoArm. ZoncoArm support; www.zoncoarm.com; retrieved January 2, 2012

3. Focal Meditech; www.focalmeditech.nl; retrieved January 2, 2012

4. Herder J. Development of a statically balanced arm support: Armon. Proceedings of the $9^{\text {th }}$ International Conference on Rehabilitation Robotics (ICORR) 2005, Chicago; 2005; pp 281-286

5. Perry JC, Rosen J, Burns S. Upper-limb powered exoskeleton design. IEEE/ASME Transactions on Mechatronics 2007;12(4):408-417; doi:10.1109/TMECH.2007.901934

Keywords: robotics, actuatronics, smart arm support, exoskeletons

Affiliation: Eindhoven University of Technology, Eindhoven, Netherlands; E: b.v.ninhuijs@tue.nl Full paper: No

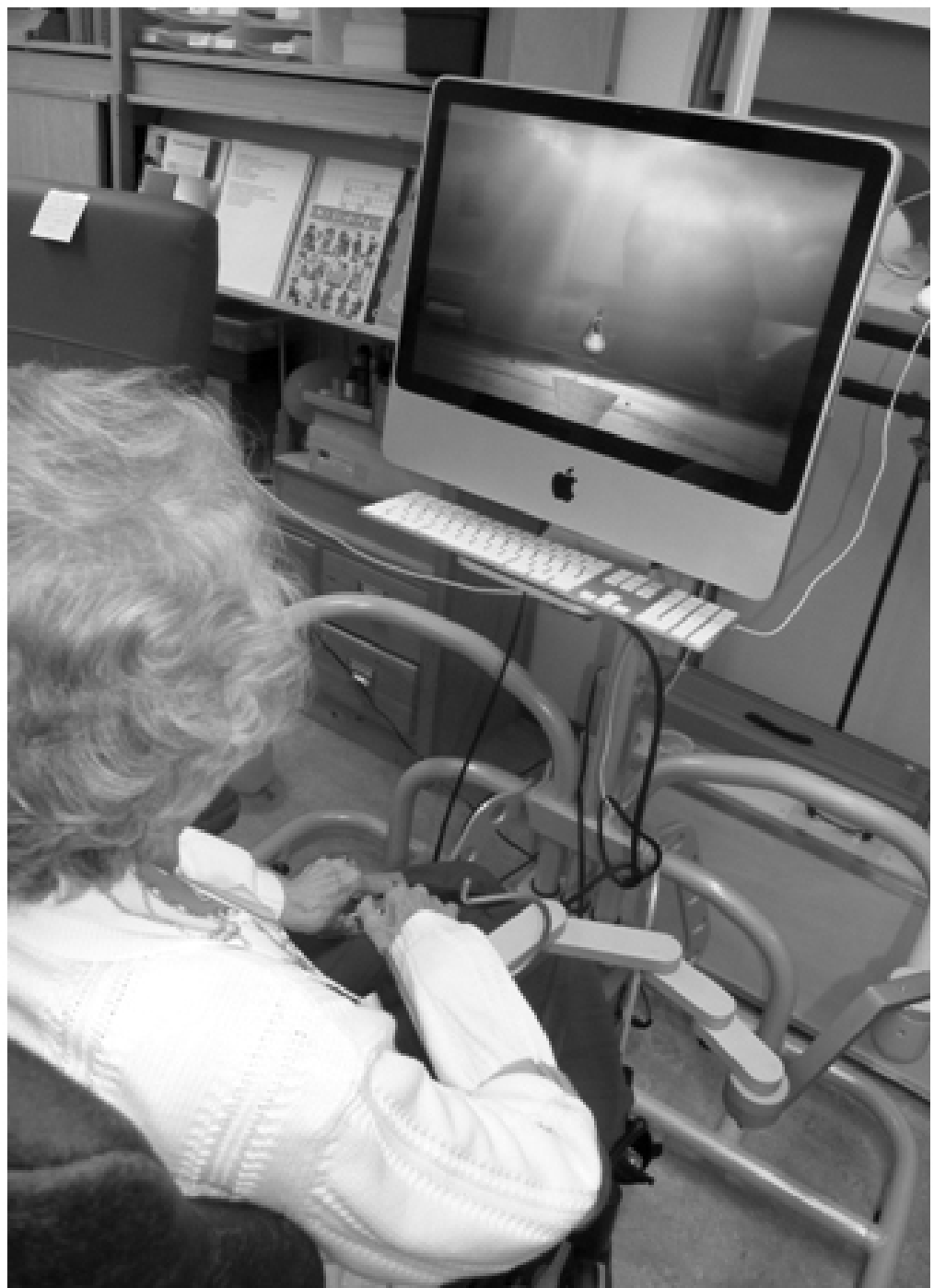

Figure 1. Playing a game using the supported human arm as a joystick 